Wiraraja Medika : Jurnal Kesehatan
https://www.ejournalwiraraja.com/index.php/FIK
2088-415x (Print) |2685-9998 (online)

\title{
Perbandingan Metode Arima Box-Jenkins dan Holt-Winters No Seasonal pada Peramalan Jumlah Penderita ISPA di Kota Malang
}

\author{
Nanta Sigit ${ }^{1^{*}}$, Arief Setiyoargo ${ }^{2}$ \\ ${ }^{1,2}$ STIKES Panti Waluya Malang \\ Nantasigit1991@gmail.com** \\ *Corresponding Author
}

\begin{tabular}{l}
\hline Informasi artikel \\
\hline Sejarah artikel: \\
Received: $29-09-2021$ \\
Revised: $21-10-2021$ \\
Accepted: 29-11-2021 \\
\hline Kata kunci: \\
Penyakit ISPA \\
Model ARIMA Box Jenkins
\end{tabular}
\begin{abstract}
ABSTRAK
ISPA adalah penyakit saluran pernapasan akut dengan perhatian khusus pada radang paru (ISPA), dan bukan penyakit telinga dan tenggorokan. Dalam rangka membuat perencanaan menurunkan jumlah penderita ISPA di daerah dengan prinsip efektif dan bertanggung jawab diperlukan perkiraan peramalan yang valid. Adanya selisih yang relatif cukup besar antara target dan capaian dalam menanggulangi penderita ISPA Kota Malang selama tahun 2017-2020, dan mengingat pentingnya peramalan sebagai indikator menurunkan penderita ISPA, maka dipandang perlu melakukan penelitian mengenai penerapan model Box-Jenkins dalam peramalan penderita ISPA. Penelitian ini bertujuan untuk membuat model estimasi penderita ISPA kabupaten malang dengan mengunakan data dinkes dari tahun 2017 sampai dengan tahun 2020. Teknik analisis yang diterapkan adalah model Box-Jenkins atau Autoregresive Integreted Moving Average (ARIMA). Hasil penelitian menunjukkan bahwa dengan menggunakan data dinas kesehatan Kota malang tahun 2014 sampai dengan tahun 2019, disimpulkan bahwa model peramalan yang terbaik adalah dengan $\operatorname{ARIMA}(1,1,0)$. Peneliti berharap metode peramalan dan hasil peramalan tersebut dapat digunakan sebagai tambahan informasi bagi pihak dinas kesehatan di Kota malang dalam menentukan kebijakan yang harus diambil dalam pencegahan penderita ISPA sesuai kebutuhan pasien di Kota Malang.
\end{abstract}

Key word:

ISPA Disease

ARIMA Box Jenkins Model

\begin{abstract}
ISPA is an acute respiratory disease with special attention to pneumonia (ISPA), and not an ear and throat disease. In order to make plans to reduce the number of ISPA sufferers in the regions with effective and responsible principles, valid forecasts are needed. There is a relatively large difference between targets and achievements in tackling ISPA sufferers in Malang City during 2017 - 2020, and given the importance of forecasting as an indicator of reducing ISPA sufferers, it is deemed necessary to conduct research on the application of the Box-Jenkins model in forecasting ISPA patients. This study aims to create an estimation model for patients with ISPA in Malang Regency using data from the Health Office from 2017 to 2020. The analytical technique applied is the Box-Jenkins model or the Autoregressive Integrated Moving Average (ARIMA). The results showed that by using data from the Malang City Health Office from 2014 to 2019, it was concluded that the best forecasting model was ARIMA $(1,1,0)$. Researchers hope that the forecasting method and forecasting results can be used as additional information for the health department in Malang City in determining policies that must be taken in the prevention of ISPA sufferers according to the needs of patients in Malang City.
\end{abstract}

\section{PENDAHULUAN}

Kesehatan merupakan kebutuhan dasar setiap manusia dan merupakan modal setiap warga negara dan setiap bangsa dalam mencapai tujuannya dan mencapai kemakmuran. Seseorang tidak bisa memenuhi seluruh kebutuhan hidupnya jika dia berada dalam kondisi tidak sehat. 
Sehingga kesehatan merupakan modal setiap individu untuk meneruskan kehidupannya secara layak. Penilaian indikator dalam kesejahteraan masyarakat dapat diukur melalui penghitungan indeks kesejahteraan, beberapa diantaranya adalah menggunakan Human Development Indeks (HDI) dan Indeks Kesejahteraan Rakyat (IKRAR). Tingkat kesejahteraan negara Indonesia masuk dalam lima besar dari 22 negara Indeks Global dari nilai 61,0 menjadi 65,4 di awal 2019. Jawa Timur termasuk Kota Malang memiliki nilai Indeks Kesejahteraan Rakyat (IKRAR) dalam rentang antara 39.01-46.00 pada tahun 2010 yang menunjukkan bahwa tingkat kesejahteraan masyarakat di Jawa Timur dikategorikan pada tingkat sedang (Menkokesra, 2012).

Peningkatan level kesejahteraan masyarakat dapat dilakukan melalui peningkatan derajad kesehatan dan ekonomi masyarakat sebagai salah satu indikator. Salah satu cara peningkatan derajat kesehatan masyarakat melalui program pendekatan promotif, pencegahan dan kuratif, rehabilitatif. Menurut riskesdas 2018 untuk prevalensi penyakit ISPA di Jawa Timur terdapat sekitas 6\%, sedangkan untuk prevalensi ISPA di Kota Malang menurut Riskesdas 2018 terdapat sekitar 4\%. Dari data diatas maka perlu dilakukan promotif, pencegahan dan kuratif untuk mencegah terjadinya peningkatan infeksi lebih lanjut terhadap penderita tetapi juga mencegah terjadinya penularan penyakit kepada orang-orang sekitar penderita.

Target dalam mencapai upaya pencegahan dan perbaikan status kesehatan sangat dibutuhkan kolaberasi yang efektif dan komunikatif antara masyarakat dengan tenaga kesehatan profesional. Jumlah tenaga kesehatan profesional yang sangat terbatas, sehingga mengharuskan masyarakat dapat menjadi partner bagi tenaga kesehatan di sektor promotif kesehatan.

Kerjasama dengan masyarakat diperlukan di sektor promotif karena tenaga kader kesehatan di masyarakat merupakan salah satu penggerak pembangunan khususnya di bidang kesehatan. Mereka secara swadaya dilibatkan oleh pemerintah dalam kegiatan pelayanan kesehatan yang salah satunya adalah pemberian pelayanan kesehatan kepada masyarakat. Tanpa mereka kegiatan pelayanan kesehatan di masyarakat tidak banyak artinya. Kader kesehatan bertugas melaksanakan edukasi pada masyarakat. Pelaksanaan intervensi pemberian edukasi dilakukan berdasarkan permasalahan yang terjadi dimasyarakat yang menyangkut penyakit ISPA. Prevalensi yang banyak untuk penyakit menular yang ada pada masyarakat salah satunya adalah Infeksi Saluran Nafas Atas (ISPA). Fenomena ini menjadi alasan pengabdian masyarakat dilaksanakan kepada para kader kesehatan di masyarakat, sehingga dapat meningkatkan kesehatan di masyarakat melalui strategi pemberian edukasi pada kader kesehatan yang ada dimasyarakat didaerah Kota Malang. Maka kali ini, peneliti mencoba meramal penderita ISPA di Kota malang menggunakan Metode Arima BoxJenkins Dan Holt-Winters No Seasonal yang bertujuan metode peramalan dan hasil peramalan tersebut dapat digunakan sebagai tambahan informasi dalam menurunkan penderita ISPA di kota malang.

\section{METODE PENELITIAN}

Untuk meramalkan penderita ISPA dalam kurun waktu yang cukup lama, data sekunder diambil dari tahun 2017 sampai dengan tahun 2020 dengan jumlah 48 data bulanan. Data bersumber dari Dinas Kesehatan Kota Malang dengan variable penderita ISPA di kota malang, yang selanjutnya dianalisis dengan menggunakan model Box-Jenkins. Box dan Jenkins mempopulerkan metode peramalan data univariat runtut waktu yang terdiri dari 3 tahap dalam memilih model yang cocok untuk melakukan estimasi dan peramalan. Peramalan (forecasting) dengan menggunakan data runtun waktu (time series) secara sederhana sering dilakukan dengan analisis trend. Namun agar hasil peramalan lebih akurat, terutama untuk data runtun waktu yang cukup panjang, maka data runtun waktu dapat dianalisis dengan mempertimbangkan berbagai perilaku data melalui berbagai model antara lain model autoregressive (AR), moving average (MA) dan autoregressive moving average (ARIMA) (Wei, 2011), yang dijelaskan sebagai berikut.

\section{HASIL DAN PEMBAHASAN}

Untuk meramalkan penderita ISPA dalam kurun waktu yang cukup lama, yaitu dari dari tahun 2017 sampai dengan tahun 2020. Data bersumber dari Dinas Kesehatan Kota Malang, yang selanjutnya dianalisis 
dengan menggunakan model Box Jenkins. Box dan Jenkins mempopulerkan metode peramalan data univariat runtut waktu yang terdiri dari 3 tahap dalam memilih model yang cocok untuk melakukan estimasi dan peramalan. Peramalan (forecasting) dengan menggunakan data runtun waktu (time series) secara sederhana sering dilakukan dengan analisis trend. Namun agar hasil peramalan lebih akurat, terutama untuk data runtun waktu yang cukup panjang, maka data runtun waktu dapat dianalisis dengan mempertimbangkan berbagai perilaku data melalui berbagai model antara lain model autoregressive (AR), moving average (MA) dan autoregressive moving average (ARIMA) (Wei, 2011), yang dijelaskan sebagai berikut. Dilakukan analisis terhadap metode yang digunakan, yaitu metode ARIMA pada data jumlah penderita ISPA di kota malang. LangkahLangkah melakukan metode peramalan ARIMA Box Jenkins.

Jika kita lihat pada Time Series plot pada Gambar 1 dapat diketahui bahwa pola data pada data penderita ISPA belum stasioner dalam varian tetapi belum stasioner dalam mean. Dari Gambar 2, menunjukkan bahwa nilai lamda -2, hal ini stasioner dalam varian tidak terpenuhi dan dilakukan uji ransformasi varian yang ke- 1 . Didapatkan hasil pada Gambar 3 dibawah ini.

Dari Gambar 3 menunjukkan nilai lamda sebesar 1. Hal ini dapat ditarik kesimpulan stasioner dalam varian apabila lamda sebesar 1. Stasioner dalam varian sudah terpenuhi dan dilanjukan kedalam uji stasioner dalam mean. Untuk bisa memastikan data stasioner dalam varian dapat dilihat pada Gambar 3. Pada uji yang dilakukan di Gambar 3 dengan menggunakan transformasi Box - Cox, dari transformasi tersebut diperoleh nilai $\lambda$ sebesar 1 yang menunjukkan bahwa varian stabil. Sebaliknya, untuk melihat data stasioner dalam rata - rata dapat dilihat dari Gambar 4 plot ACF penderita ISPA dan Gambar 5 plot PACF penderita ISPA. Berdasarkan identifikasi diatas maka pendugaan model untuk penderita ISPA kota malang yaitu ARIMA $(1,1,0)$.

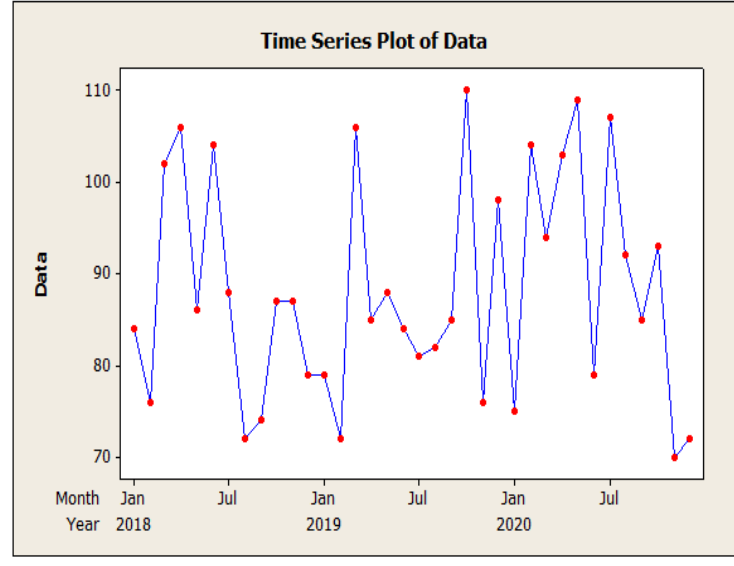

Gambar 1. Time Series Plot Penderita ISPA di Kota Malang

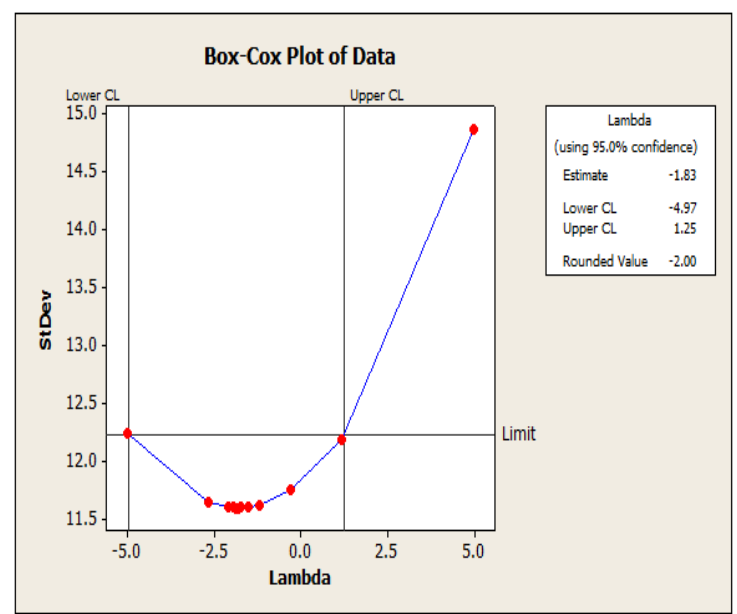

Gambar 2. Transformasi Box-Cox Penderita ISPA di Kota Malang

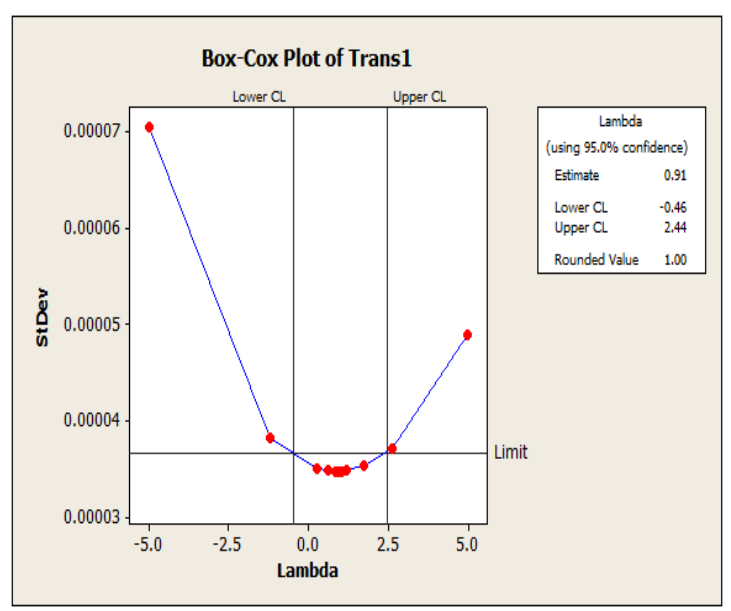

Gambar 3. Transformasi Box-Cox penderita ISPA di Kota Malang 


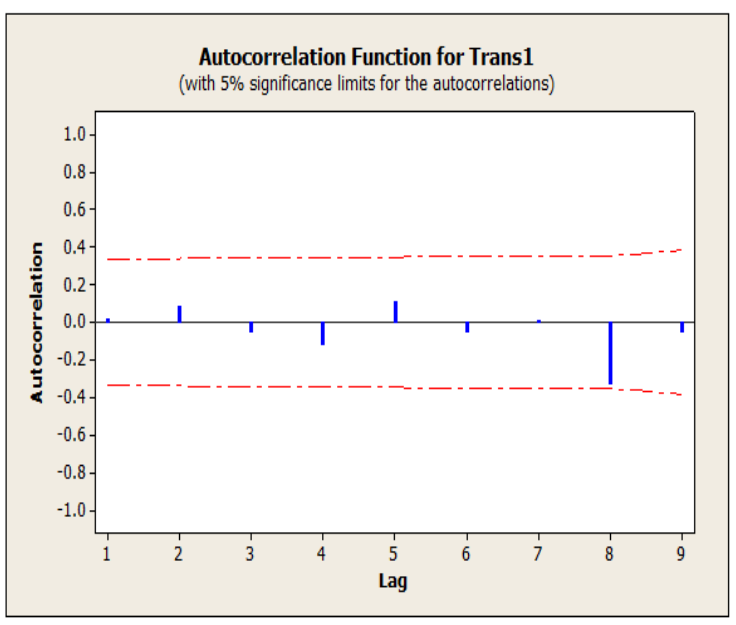

Gambar 4. Plot Autocorrelation (ACF) Penderita ISPA

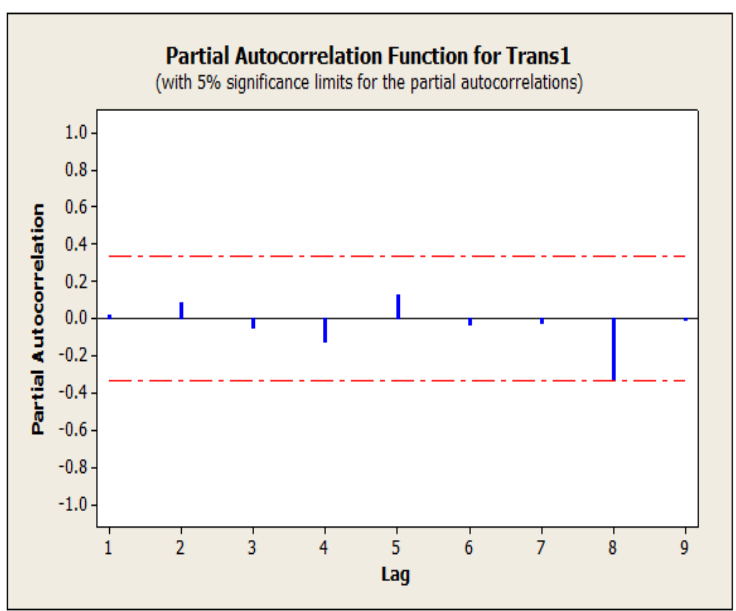

Gambar 5. Plot Partial Autocorrelation (PACF) penderita ISPA

Setelah dilakukan pendugaan awal model ARIMA dengan melihat plot ACF dan PACF maka dilakukan pengujian parameter. Pengujian parameter digunakan untuk menunjukkan apakah parameter sudah signifikan terhadap model atau layak untuk dijadikan model. Pengujian parameter dilakukan dengan menggunakan statistik uji t-student atau dengan membandingkan nilai p-value yang didapat dari output komputer dengan nilai $\alpha$ yang digunakan.

Tabel 1. Uji Signifikasi Model ARIMA Penderita ISPA

\begin{tabular}{cccc}
\hline ARIMA & Parameter & Pvalue & Keputusan \\
\hline \multirow{2}{*}{$(1,1,0)$} & $\mathrm{AR}(1)$ & 0.586 & Signifikan \\
\hline \multirow{2}{*}{$(1,1,1)$} & $\mathrm{AR}(1)$ & 0.866 & $\begin{array}{c}\text { Tidak } \\
\text { Signifikan }\end{array}$ \\
\cline { 2 - 4 } & $\mathrm{MA}(1)$ & 0.000 & Signifikan \\
\hline
\end{tabular}

Dalam suatu pemodelan, seluruh parameter yang digunakan harus signifikan. Berdasarkan pada Tabel 1 dapat dilihat bahwa nilai $p$-value pada parameter dari model ARIMA $(1,1,0)$ kurang dari $\alpha$, sehingga berdasarkan $\mathrm{p}$-value, parameter model ARIMA $(1,1,0)$ tersebut adalah signifikan sehingga parameter pada model tersebut baik untuk digunakan.

Setelah selesai menaksir masingmasing parameter dari model ARIMA untuk data penderita hipertensi maka selanjutnya dilakukan pemeriksaan diagnostik dengan memeriksa residual apakah white noise berdistribusi normal. Hal ini bertujuan untuk membuktikan bahwa model ARIMA tersebut telah memadai. Pemeriksaan white noise apabila antara residualnya tidak terjadi korelasi sehingga pada residualnya tidak terdapat model.

Tabel 2. Pemeriksaan White Noise pada Penderita ISPA

\begin{tabular}{ccccc}
\hline ARIMA & Lag & Ljung-Box & P_value & Keputusan \\
\hline \multirow{2}{*}{$(1,1,0)$} & 12 & 12.4 & 0.259 & Tolak H0 \\
\cline { 2 - 5 } & 24 & 22.7 & 0.417 & Tolak H0 \\
\hline
\end{tabular}

Berdasarkan Tabel 2 tentang pengujian white noise untuk data penderita hipertensi model ARIMA yang sudah white noise nilai P_value $>\alpha$. Berdasarkan uraian diatas, dapat disimpulkan bahwa berdasarkan uji kesesuaian model, model yang sesuai untuk digunakan pada data penderita ISPA adalah $\operatorname{ARIMA}(1,1,0)$. 


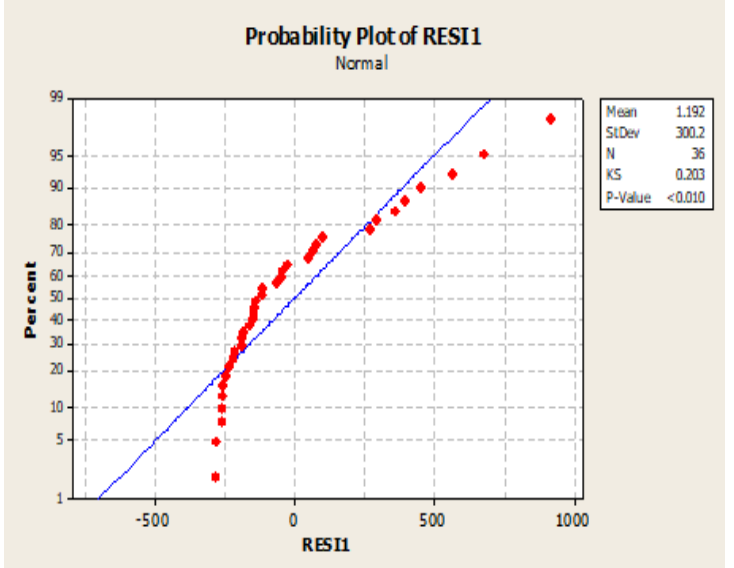

Tabel 3. Hasil Ramalan Penyakit ISPA di Kota Malang

\begin{tabular}{cccc}
\hline Tahun & Bulan & Arima & Winter \\
\hline \multirow{2021}{*02}{} & Januari & 88.367 & 76.6017 \\
\cline { 2 - 4 } & Februari & 88.393 & 80.4971 \\
\cline { 2 - 4 } & Maret & 88.42 & 94.2175 \\
\cline { 2 - 4 } & April & 88.446 & 90.2976 \\
\cline { 2 - 4 } & Mei & 88.472 & 86.0798 \\
\hline Juni & 88.498 & 79.029 \\
\hline Juli & 88.525 & 81.2514 \\
\hline Agustus & 88.551 & 71.2389 \\
\cline { 2 - 4 } & September & 88.577 & 69.2238 \\
\cline { 2 - 4 } & Oktober & 88.603 & 80.6307 \\
\cline { 2 - 4 } & November & 88.629 & 63.2959 \\
\cline { 2 - 4 } & Desember & 88.656 & 66.5847 \\
\hline
\end{tabular}

Pada data penderita ISPA ketika dilakukan pemeriksaan terhadap kenormalan diketahui bahwa dengan melihat nilai $\mathrm{p}$-value residual dari model pada penderita ISPA mengikuti distribusi normal. Hal ini dapat dilihat nilai p-value dari model ARIMA $(1,1,0)$ memiliki nilai lebih dari $\alpha$ yang digunakan yaitu $5 \%$, yaitu sebesar > 0,203 sehingga keputusan yang diambil adalah gagal tolak H0, yaitu residual mengikuti distribusi normal.

\section{Pebandingan Peramalan ARIMA $(1,1,0)$ dan Winters}

Setelah didapatkan model terbaik dari data penderita ISPA, maka dilakukan peramalan dengan menggunakan model yang didapatkan yaitu $\operatorname{ARIMA}(1,1,0)$ dan Winters pada data penderita ISPA. Hasil peramalan jumlah pasien ISPA ini untuk periode 12 bulan ke depan seperti yang dapat dilihat pada Tabel 3.
Tahap selanjutnya setelah pemeriksaan asumsi white noise adalah melakukan pemeriksaan kenormalan residual pada masing- masing model ARIMA. Uji asumsi distribusi normal ini bertujuan untuk mengetahui apakah residual data telah memenuhi asumsi kenormalan atau belum. Untuk melakukan pemeriksaan Ini digunakan Uji Kolmogorov Smirnov di Gambar 6.

\section{Pemilihan metode terbaik dilihat dari Error}

Pemilihan model terbaik dari kedua model, dapat dilakukan dengan melihat perbandingan nilai error yang terkecil. Perbandingan error ini dapat dilihat pada tabel 4 .

Tabel 4. Perbandingan Nilai Error

\begin{tabular}{cc}
\hline Metode & Error \\
\hline Winter & 197.25 \\
\hline ARIMA(1,1,0) & 123.781 \\
\hline
\end{tabular}

Dari kedua metode tersebut, maka dapat disimpulkan bahwa metode $\operatorname{ARIMA}(1,1,0)$ lebih bagus digunakan dalam peramalan ISPA dikarenakan memiliki error terkecil.

\section{KESIMPULAN}

Dari analisis dan pembahasan yang dilakukan pada bab sebelumnya maka dapat diambil beberapa kesimpulan berdasarkan tujuan penelitian yaitu: Dari kedua metode tersebut, maka dapat disimpulkan bahwa metode $\operatorname{ARIMA}(1,1,0)$ lebih bagus digunakan dalam peramalan ISPA dikarenakan memiliki error terkecil. Bagi dinas kesehatan agar lebih memperhatikan daerah-daerah yang memiliki jumlah terbesar pasien ISPA sebagai prioritas, terutama daerah yang terpencil. Dan memberikan sosialisasi dan pasokan stok obat untuk penderita ISPA. Sebaiknya dalam pengambilan sampel data tidak terlalu sedikit sehingga didapatkan hasil peramalan yang tepat dan dapat memenuhi kriteria. Dan dalam penghitungan in sample dan out sample harus lebih teliti.

\section{DAFTAR PUSTAKA}

Anisyah, Luluk, \& Sigit, Nanta. (2020). Pemberian Edukasi Terkait Hipertensi Kepada Pendamping/Pengasuh Di Panti Werdha Lansia Pangesti Lawang Kabupaten Malang. Jurnal Pelayanan 
dan Pengabdian Masyarakat (Pamas), 4(2), 91-99.

RI, Kemenkes. (2010). ISPA Balita Buletin Jendela Epidemiologi Vol. 3.

RI, Kemenkes. (2011). Pedoman Pengendalian Infeksi Saluran Pernafasan Akut. Dirjen Pengendalian Penyakit dan Penyehatan Lingkungan

RI, Kemenkes. (2011). Standar Antropometri Penilaian Status Gizi Anak

RI, Kemenkes. (2012). Pedoman Pemberantasan Penyakit Infeksi Saluran Pernapasan Akut untuk Penanggulangan ISPA pada Balita

RI, Kemenkes. (2014). Penanggulangan Penyakit Menular

RI, Kemenkes. (2015). Rencana Strategis Kementerian Kesehatan Tahun 20152019.

Sigit, Nanta, \& Marbun, Romaden. (2021). UPAYA PENCEGAHAN JUMLAH PENDERITA PNEUMONI DI MASYARAKAT DI ERA PANDEMI COVID 19. SELAPARANG Jurnal Pengabdian Masyarakat Berkemajuan, 4(3), 815819.

Sigit, Nanta, \& PK, Ida Ayu. (2021). Perbandingan Model Transfer Function Dan Model Neural Network Untuk Prediksi Banyak Kasus Demam Berdarah Di Kota Malang. Jurnal Ilmu Kesehatan MAKIA, 11(1), 1-9.

Sigit, Nanta, \& Setiyoargo, A. (2020). Analisis Peramalan Jumlah Penderita Hipertensi Pada Lansia Di Kabupaten Malang Menggunakan Metode Arima BoxJenkins. Jurnal Rekam Medis dan Informasi Kesehatan, 3(1).

Sigit, Nanta, \& Setiyoargo, A. (2020). Analisis Peramalan Jumlah Penderita Hipertensi Pada Lansia Di Kabupaten Malang Menggunakan Metode Arima BoxJenkins. Jurnal Rekam Medis dan Informasi Kesehatan, 3(1).

Sigit, Nanta, \& Sugiyanto. (2021). Optimalisasi Peran Kader Kesehatan Dalam Upaya Penurunan Jumlah Penderita ISPA di Era Pandemi Covid 19.
Jurnal ABDIMASA Pengabdian Masyarakat, 4(2).

Sigit, Nanta, Debora, Oda, \& Lahardo, Devanus. (2020). Pemberdayaan Masyarakat Dalam Penerapan Self Management Untuk Mencegah Hipertensi Pada Lansia Di Dusun Sukosari Desa Pandansari, Poncokusumo, Kabupaten Malang. ABDIMAS UNWAHAS, 5(2).

W, Makridakis, \& Gee, Mc. (2013). Metode dan Aplikasi Peramalan Vol. 2.

Wei, W., W. S. (2011). Time Analysis Univariate and Multivariate Methods 